\title{
SANTOS E CONTRABANDISTAS: A NACIONALIZAÇÃO DE SÃO SEBASTIÃO E A FRONTEIRA AUSTRAL ARGENTINO-CHILENA*
}

Rolando J. Silla

É comum contrapor-se a religião a processos nacionalistas, associados em princípio ao "profano". Encontramos assim, em um estudo do tema tão transcendente como Comunidades imaginadas, de Benedict Anderson, a afirmação de que o nacionalismo substituiu o universalismo da religião imperante durante as monarquias e a consideração de que o surgimento do nacionalismo na Europa Ocidental corresponde ao crepúsculo do pensamento religioso no século XVIII. A religião transmuta-se em nacionalismo, e os imaginários culturais religiosos transformam-se em imaginários nacionalistas (2000:29).

Esta afirmação provocou críticas como a de Claudio Lomnitz, que fez notar que, por exemplo, na América Hispânica o nacionalismo se baseou fundamentalmente na apropriação da "fé verdadeira" promulgada pela Igreja Católica (2001:48). Anderson esqueceu-se da emergência, em toda a América Hispânica durante a colônia, de um sincretismo religioso expresso na arte barroca e nas mariologias coloniais; e do surgimento de símbolos religiosos de identidade plural (hispano-indígena) que, com o tempo, se transformariam em poderosos instrumentos de afirmação das nacionalidades, como a Virgem de Guadalupe no México, Santa Rosa no Peru e Caacupé no Paraguai. A importância política desses fenômenos pareceu residir na geografia sagrada e política que simultaneamente conseguiram inventar.

Como cientistas sociais, defendemos amiúde, talvez devido à nossa própria formação acadêmica, uma versão laica dos fatos que investigamos. Acreditamos ser, dessa forma, mais objetivos em nossas afirmações. Mas quando nos encontramos diante de nossos informantes, e ainda mais se convivemos algum tempo com eles, damo-nos conta de dimensões que muitas vezes consideramos supérfluas, como o fato de que, para eles, a 
religião é um fator de grande importância em suas vidas. Perguntamonos então por que em muitas ocasiões isto acaba sendo "esquecido". Damo-nos conta também de que, para além de suas convicções pessoais, esse fenômeno não pôde passar despercebido dos agentes estatais que efetivaram a territorialização dos Estados nacionais.

Por isso, o presente artigo retoma esse tema de uma perspectiva etnográfica: em algum momento da década de 40, um grupo de habitantes da localidade argentina de Las Ovejas adquiriu e importou uma imagem de São Sebastião do povoado vizinho de Yumbel, no Chile. Embora se afirme que isto se passou no verão de 1946, não existem documentos a respeito e, conseqüentemente, a data exata do traslado, o (ou os) responsável pela decisão, assim como as circunstâncias que motivaram a importação, não são totalmente claros. Seja como for, São Sebastião, um santo de devoção principalmente chilena, teve desde então uma sede oficial na Argentina.

Os diversos relatos sobre a travessia da imagem de São Sebastião serão nossa fonte principal. Desnecessário chamar a atenção para a importância do papel desempenhado pelas ordens religiosas e seus missionários no processo de homogeneização cultural daqueles contingentes que foram finalmente integrados a uma "tradição argentina". Transformação que implicou uma profunda reacomodação e reinvenção de novos centros e periferias, implicando novos atores sociais (como os contrabandistas), novas relações de força (exercida pela guarda de fronteiras, Gendarmeria Nacional) e novos sentidos do legal e do ilegal (na distinção entre comércio e contrabando).

Tudo isso indica que embora as pretensões dos governos a respeito de determinados territórios criem certos precedentes, as nações não são preexistentes, porém se "inventam" a partir de uma série de ações concretas que acabam por efetivar e tornar reais os Estados nacionais. Mas esta invenção não é sinônimo de falso, ilegítimo ou sem eficácia. Quando falo de invenção o faço no sentido proposto por Roy Wagner (1981), como algo positivo e esperado na vida dos seres humanos, como uma criação que, em diálogo permanente com as tradições preexistentes, forma outras tantas que passam a fazer parte da vida cotidiana e da própria tradição. Nesse sentido, sim, sigo Anderson, ao considerar que as comunidades imaginadas que são as nações não devem distinguir-se por sua falsidade ou legitimidade, mas antes pelo estilo segundo o qual são imaginadas (2000:24).

Os relatos analisados também nos obrigarão a refletir sobre conceitos muitas vezes utilizados, como o de "fronteira natural", ou sobre a tese local 
de "muralha andina". No nosso caso, a Cordilheira dos Andes, que os habitantes de Las Ovejas tiveram de atravessar para importar a imagem de São Sebastião, é uma barreira natural entre a Argentina e o Chile. Isto é reconhecido desde a época colonial, quando se distinguiram as diferentes atribuições do vice-reinado do Rio da Prata e da Capitania Geral do Chile. De fato, a altura dessa cadeia de montanhas faz com que os invernos sejam especialmente longos e com grandes nevascas, dificultando o tráfico transandino. Mas esses inconvenientes não são obstáculos intransponíveis. Entre as cadeias montanhosas existem passagens que, para quem as conhece, permitem a comunicação entre o oriente e o ocidente da cordilheira. Este conhecimento social torna relativa a barreira natural. Estudos recentes de historiografia e antropologia sobre a fronteira argentino-chilena insistem que enquanto para ambos os Estados a Cordilheira dos Andes foi considerada como um limite internacional natural, para seus habitantes andinos vem sendo há séculos, antes que um limite, o centro de relações sociais. Neste artigo, veremos que esta afirmação é relativa e que nos discursos oficiais subsiste uma disputa entre a idéia de barreira andina e a de direitos históricos que a nega. Por outro lado, os aspectos religiosos, assim como as transformações devidas aos agentes concretos do Estado que chegaram à região, não foram até o momento suficientemente analisados. Esta é a lacuna que tentarei preencher com este artigo ${ }^{1}$.

\section{A invasão Argentina do Alto Neuquén}

O que hoje se denomina Alto Neuquén ou Zona Norte (região onde se localiza Las Ovejas) foi durante os séculos XVIII e XIX controlado por indígenas mapuche-pehuenches que o utilizaram como lugar de paragem e engorda de animais que obtinham no Atlântico, fosse por criação, fosse por saque às populações crioulas em incursões conhecidas como malón, palavra indígena que significa a ação de hostilizar o inimigo ofendendoo ou saqueando-o (Rosas 1995:218). Também, entre 1813 e 1830, foi um refúgio dos grupos realistas associados aos Pehuenches que se opunham à independência chilena (Bechis 2001:72). Posteriormente lá existiu uma população crioula estável dedicada à agricultura e à pecuária, controlada por um comissário que administrava a justiça em nome do Estado chileno até 1879. Pouco depois, o capitão Recabarren tomou o assentamento para a Argentina (Fernández 1965:12).

Uma vez invadida a Zona, a administração central de Neuquén foi estrategicamente instalada no Forte da IVa Divisão, depois denominado 
cidade de Chos Malal. Esta foi capital do Território Nacional de Neuquén de 1887 até 1904, quando foi transferida para o atual departamento de Confluencia, no centro-este da província. Em fins do século XIX havia várias razões para instalar o centro administrativo do território no Alto Neuquén, como a presença de contingentes nativos importantes em número que deviam ser contidos. Mas também se considerou um possível conflito entre Estados e por isso se oficiou um critério de segurança e defesa militar controlando as passagens transandinas em um momento em que se temia um enfrentamento bélico com o Chile (Bandieri 1993:161).

Com a chegada do exército argentino iniciou-se o processo de territorialização e nacionalização dessas populações, procurando homogeneizar indivíduos e grupos autodeclarados como mapuches-pehuenches ou chilenos em torno de uma nova identificação: a de argentino. No entanto, isto se dará de forma paulatina. Na verdade, o período 1895-1930 caracterizou-se por uma presença estatal quase nula no que se denominou Território Nacional de Neuquén. Por isso, a anexação militar não teve correlação com a integração em outros aspectos, que continuaram sob a hegemonia do Pacífico. A falta de controle fronteiriço e as conexões históricas que as populações do Alto Neuquén mantinham com as povoações do Pacífico fizeram com que tanto os cronistas quanto a historiografia atual considerassem que o grosso da população era de origem chilena. De minha parte, alegarei que a categoria de chileno é no mínimo imprecisa quando aplicada ao Alto Neuquén antes da década de 60, como evidencia em certa medida a própria confusão produzida na população tendo em vista a invasão militar e a implantação de um limite internacional. Se considerarmos que desde o século XVI a zona do Pacífico conquistada pela monarquia espanhola era denominada Capitania Geral do Chile, podemos dizer que seus habitantes devem ser denominados chilenos. Mas esta não é uma categoria de identificação nacional, e sim burocrática, pois a Capitania era apenas uma unidade administrativa do império ibérico, e seus habitantes, súditos de um rei europeu. O processo de crioulização e as revoluções nacionalistas que se desenvolveram no princípio do século XIX na América transformaram gradativamente esses contingentes em chilenos, agora sim como representantes de um Estado-nação.

É provável que no Chile a nacionalização tivesse ocorrido várias décadas antes, em conseqüência de a região ser colonizada de forma precoce (Yumbel, como forte espanhol e centro de devoção a São Sebastião implementado pelos jesuítas, data do século XVI). Mas do lado argentino, por exemplo, em Las Ovejas, antes que se construíssem as pontes que fazem comunicar-se as cidades de Andacollo e Chos Malal, no final da 
década de 60, era mais prático para os nativos ir a uma cidade chilena do que a uma argentina. Por isso, no verão, junto com o gado que se levava para vender no Chile, registravam-se os nascimentos nos cartórios civis deste país. Isto fez com que muitos fossem portadores de documento de identidade chileno ainda que tivessem nascido em território argentino e os dois países consideram o jus soli como princípio legal de identificação nacional. Também devemos ter em conta que em muitos casos a autodeclaração chilena pode funcionar como uma maneira de ocultar outra identidade considerada localmente mais estigmatizante concernente aos argentinos: a de índio².

Tampouco houve integração plena no campo político. Territórios nacionais como Neuquén eram entidades jurídicas que, diferentemente das províncias, constituíam meras unidades administrativas sobre as quais o governo central devia exercer uma função de homogeneização econômica e social para atingir, quando reunissem determinado número de habitantes, a provincialização. Os habitantes que lá viviam careciam de direito ao voto para a eleição de autoridades nacionais e "territoriais"; só podiam eleger autoridades comunais. Em Neuquén, somente em 1951 os habitantes tiveram a possibilidade de participar das eleições nacionais (Arias Bucciarelli 1999:32).

Em 1895, os departamentos do norte neuquino concentravam $62 \%$ da população provincial, $68 \%$ da qual se autodeclarava chilena. Podemos considerar dois motivos para tanto. Por um lado, como já vimos, havia um assentamento dependente do governo chileno antes da chegada do exército argentino. Tratava-se de uma população crioula preexistente à constituição da nação argentina. Mas, além disso, nessa época, o governo chileno se caracterizou pela expulsão da população crioula, tendo priorizado o assentamento de imigrantes de origem européia em seu novo território conquistado aos Mapuche. Tanto a população preexistente como a migrante são confundidas nas crônicas e análises.

Estudos como os de Carmen Norabuena Carrasco (1997) ou Enrique Mases e Gabriel Rafart (1997) concordam que, durante o século XIX, se iniciou na agricultura localizada no centro e no sul do Chile (em uma latitude geográfica paralela à de Neuquén) um processo expansivo intimamente relacionado ao aumento da demanda de grãos na Europa e na Austrália. Essa expansão foi implementada em uma via dupla: a ampliação das zonas cultivadas, por um lado, e o aumento das formas de exploração camponesa, incrementando suas obrigações, por outro. Ao mesmo tempo havia um alto grau de concentração da propriedade e o governo considerou que as terras fiscais só podiam ser ocupadas por imigrantes europeus 
ou norte-americanos. A efetivação dessas radicações implicou que parte da população crioula ou nativa que previamente ocupava essas terras fosse despojada. Uma das alternativas foi atravessar a cordilheira e instalar-se na Argentina. Esta migração rural-rural pôde realizar-se devido à existência de terras livres em Neuquén, com enormes extensões de terra do Estado ou de proprietários absenteístas.

Essa primazia de população chilena também se observa nas crônicas da época. Um dos viajantes que percorreu a região entre 1903 e 1904 foi o padre salesiano Lino Carbajal, que descreveu o campesinato pobre "chileno" como de "aspecto receoso, tímido e embusteiro", comparandoo negativamente com o "gaúcho argentino, generoso, jovial e franco com todo o mundo" (1985:89). Apesar de tudo, considerou que os chilenos eram uma população suscetível de assimilar-se à nação argentina se fossem executadas as políticas adequadas e não se abusasse deles:

Os chilenos olham com receio os argentinos, que não conheceram senão revestidos de autoridade, nem sempre administrada com equanimidade. O elemento chileno trabalhador é para Neuquén um bom braço e, melhor contratado e remunerado, é a única imigração colonizadora no território (Carbajal 1985:150).

Quem é ou não é chileno nessa região e época não é detalhado com clareza. Mas o texto citado evidencia que, ao diferenciar os argentinos dos chilenos, Carbajal está realizando ao mesmo tempo uma distinção entre os que controlam o Estado e os que não o controlam. Por exemplo, o viajante refere-se a um habitante chileno chamado José Roza Flores e afirma que este homem e sua família moram ali desde 1866. Carbajal não explica essa situação. Seguramente Roza Flores, descrito como uma pessoa de uns 40 anos de idade, chileno de nascimento "mas argentino de coração", se considerava chileno, pois antes de 1880 pertencia ao grupo de crioulos que viviam sob a administração chilena. Mas, uma vez conquistado o território pelas forças argentinas, essa identificação parece não fazer sentido. Ainda que não o especifique, é provável que Carbajal considere que todo habitante que pratique a pecuária transumante seja por definição chileno, já que caracterizou a população residente no Alto Neuquén em função de sua alta mobilidade, devido principalmente a essa forma de produção:

As peregrinações nas veranadas começam em novembro, durando até os últimos dias de abril. Em geral, esses lugares estão nos vales das altas cordilheiras, e nesta zona, entre os últimos afluentes dos rios Nahuve, Varvarco e 
Neuquén Superior. Como são chilenos em sua maioria, os veraneadores internam-se até os vales, entre os maciços da cordilheira que pertencem ao Chile. Uns arrendam os vales de veraneio e outros estacionam onde lhes dão permissão ou não há outros já estabelecidos. Vamos à cordilheira, me diz, quando derreterem as neves, levando cada pastor toda sua família e pertences correspondentes. O habitual é irem todos os anos cada qual a um mesmo lugar, onde muitos têm construídos seus ranchos para se restabelecerem de possíveis nevascas (Carbajal 1985:93, ênfases minhas).

Essas viagens sazonais tornavam manifesto o escasso controle estatal sobre a fronteira internacional, já que famílias inteiras costumavam deslocar-se com seu gado para as veranadas situadas no território transandino. Isso evidencia a existência de espaços de fronteira onde seus habitantes não reconheciam jurisdições oficiais.

O relato de Carbajal também demonstra a existência de uma complementaridade comercial e ecológica entre as populações de ambos os lados da Cordilheira. Da Argentina exportava-se gado, do Chile traziamse especialmente produtos agrícolas. Este intercâmbio se evidencia por meio da memória dos habitantes do Alto Neuquén. Segundo o filho de um então importante comerciante da região, o ouro e os couros eram enviados a Buenos Aires, e às vezes o couro também provinha do Chile, uma vez que sua comercialização lá vira-se em certos períodos proibida pela legislação chilena. Quanto às peles de raposa, diz ele,

[...] os caçadores chilenos traziam-nas por cima da neve, com fardo de... bem, este comércio era importante porque tudo tinha valor, tanto as peles, quanto os couros, quanto a lã. Tudo tinha seu valor, digamos, vendia-se a bom preço. Ademais, tínhamos o ouro, e sem falar na época de verão, o mal chamado [yamado] contrabando que levava [yevava] os animais daqui para o Chile; e de lá [ayá] traziam por escambo, entre outras coisas, feijão, açúcar. Digamos que aqui não havia, porque aqui se tinha que ir muito longe para buscar açúcar. Por outro lado, o feijão não dava na montanha, porque é muito frio. A batata, então, todas essas coisas que aqui não se colhia.

Além do fato de alguns produtos terem como destino Buenos Aires, o relato evidencia que a cidade de Neuquén nem sequer era o centro econômico da Zona. Segundo Susana Bandieri (1993:154), três fatores contribuíram, no início do século XX, para intensificar o comércio ganadeiro com o Chile: a) os grandes produtores chilenos liberavam seus campos de animais para utilizá-los na agricultura; b) a província argentina de 
Mendoza, tradicional provedora de gado para o Chile, incrementou a produção vinícola, diminuindo as áreas destinadas a pastos; c) a cordilheira neuquina converteu-se em área marginal para a Argentina, pois o maior esforço de desenvolvimento do país realizou-se no pampa e no litoral. Contudo, devido à situação mediterrânea de Neuquén, o território funcionou como um espaço praticamente desvinculado do mercado argentino e integrado ao Chile.

Esta integração não foi apenas econômica: os habitantes do Alto Neuquén mantiveram, ao mesmo tempo, fortes laços culturais com populações chilenas, laços que, por outro lado, tampouco eram unidirecionais, já que a população do Pacífico também compartilhava de costumes provenientes do lado oriental. Um exemplo encontra-se em uma nota do jornal Neuquén, de Chos Malal, a respeito do Natal de 1894, na qual podemos ler que "a afluência de populações da vizinha República do Chile superará a dos anos anteriores, dado o interesse despertado pelas festas e tendo em conta que todos os anos elas congregam meia província de Bío-Bío, formando um enorme acampamento de pessoas que se divertem" (apud Frapiccini, Rafart e Lvovich 1995:344). Esses vínculos de ordem econômica e cultural favoreceram que em vários períodos da história do século XX esses contingentes populacionais fronteiriços fossem considerados por certos organismos do Estado argentino como "perigosos" e nunca totalmente assimilados à nação.

\section{A evangelização salesiana}

Até a entrada do exército argentino, o contato que a população tinha com o cristianismo era através de incursões de missionários jesuítas e, posteriormente, franciscanos provenientes do Pacífico. Pouco depois de 1880, a evangelização intensificou-se e o Alto Neuquén foi percorrido por missionários salesianos de maneira mais sistemática do que até então, com o aval do governo argentino - ainda que não sem conflitos, pois os salesianos procuraram separar-se imediatamente do exército e dos representantes do Estado por ordem expressa de seu fundador na Itália, Don Bosco. Uma vez que a violência exercida por estas instituições contra os índios recentemente dominados era incompatível com o evangelho, os salesianos deviam diferenciar-se claramente das autoridades se quisessem que a prédica desse frutos.

A dispersão da população pela Patagônia continental obrigou os salesianos a implementar missões itinerantes. No Alto Neuquén esta- 
beleceram um centro na cidade de Chos Malal e a partir dali realizaram viagens no verão para o interior da região. Durante essas travessias estivais ministravam sacramentos; o doutrinamento, porém, era rudimentar. Dessa maneira, o cristianismo chegou a todos em pouco tempo, mas sem um acompanhamento diário dos clérigos. A população tinha contato com um ou outro missionário não mais que uma ou duas vezes por ano, limitando-se ao exercício do culto cristão do batismo e a práticas individuais ou familiares, como a devoção aos santos ou a reza da novena e do rosário.

No Alto Neuquén havia devoção a vários santos que eram de especial importância; e São Sebastião era mais um, até que se introduziu a imagem. Muitos eram seus devotos, mas não o celebravam publicamente na Argentina, ao contrário, costumavam viajar até Yumbel para fazê-lo. Como a festa é de verão, a viagem não tinha finalidade exclusivamente religiosa: muitas famílias faziam suas veranadas no Chile e atravessar a cordilheira era indispensável para abastecer-se de verduras e cereais. Como diz Tito, de 60 anos e nascido na região:

São Sebastião chega [yega] mais ou menos, pelo que me lembro, em [19]48, chega aqui, [19]46 mais ou menos e, bom, não foi nada muito especial porque, bom, os santos festejamos todos. Havia os que há agora, mas quero dizer que eram todos festejados, era uma maneira de dizer, festejar, mas cada casa tinha, se não tinha São Ramón tinha Santo Antonio ou tinha a Defunta Correa, mas cada casa festejava, digamos, os santos; e então chegou [yego] São Sebastião, que era mais conhecido por causa dos limites nossos com Chillan [localidade chilena].

Quando Tito diz que "os santos festejamos todos", refere-se aos "onomásticos", ou seja, à comemoração do dia do santo que dá nome a uma pessoa, comemoração que é mesmo mais importante que a celebração de seu aniversário. A de São João era a mais famosa e sua data corresponde ao winoy xipantu (ano novo mapuche), ao qual os salesianos sobrepuseram o festejo do santo. Os três dias de duração, São João, São Joãozinho e São Joãozão, correspondiam aos dias 24, 25 e 26 de junho, respectivamente. Na noite de 24, a celebração começava onde morasse alguém chamado Juan ou Juana, situação habitual em meados do século XX. Era um festejo semipúblico, já que a princípio qualquer vizinho podia comparecer: o anfitrião oferecia comida aos presentes, recebia as cantoras (mulheres encarregadas da música), dançava-se e faziam-se testes de adivinhação do futuro. 
A inculcação do culto aos santos foi uma das maneiras pelas quais se cristianizou a população. Para isso, os missionários procuraram nexos entre o cristianismo e as tradições preexistentes. São Sebastião para espanhóis ou crioulos, a festa de São João sobreposta ao winoy xipantu para os Mapuche. Práticas que, na medida em que a população se crioulizou, foram-se mesclando e homogeneizando para toda a população. Seu êxito provavelmente explica-se pelo aspecto meramente pragmático da relação entre o crente e o santo, pela prescindência relativa de um profissional religioso para realizar essas manipulações do extraordinário e pelo fato de que não implicavam necessariamente a reunião e a formação de congregações. Cada crente podia fazer uso de seu santo de forma individual e no momento em que desejasse. Essa modalidade difundiu o cristianismo, ainda que impondo a ele uma forma particular, menos pressionada pelo peso institucional da igreja e de seus clérigos e, portanto, com maior margem de ação individual. São Sebastião era o único santo de festejo que excedia o grupo doméstico e vizinhos imediatos e que estava diretamente sob o controle da Igreja Católica. Mas sua celebração não se realizava no recém-fundado território neuquino, e sim na cidade chilena de Yumbel; o que não deixava de ser um problema para as autoridades argentinas.

\section{A chegada da imagem de São Sebastião em Las Ovejas}

Uma das prioridades dos salesianos era fixar a população seminômade, uma vez que a pecuária transumante forçava as famílias a habitar de modo sazonal vários lugares do Alto Neuquén, ou mesmo no Chile, o que, na concepção desses religiosos, dificultava a evangelização. Uma das formas encontradas para assentar a população foi por meio da instalação de capelas com seus respectivos padroeiros. Dessa maneira, missionários como Marcelo Gardín desempenharam um importante papel na região. Missionário salesiano e pároco radicado em Chos Malal entre 1937 e 1970, Gardín teve grande ascendência sobre os habitantes do Alto Neuquén e ainda hoje é lembrado pelos mais velhos. Foi sua intenção fundar capelas na região com seus respectivos santos. É atribuído a ele o fomento da construção de mais ou menos dezesseis capelas naquela zona. A imagem de São Sebastião em Las Ovejas seria produto disso, como a de Los Menucos, dedicada a São João, ou a da Virgem de Andacollo para a cidade homônima ${ }^{3}$.

Debruçado no diário e demais notas de Gardín, o missionário salesiano Oscar Barreto (1985:92) alega que aquele foi pessoalmente ao Chi- 
le procurar a imagem para Las Ovejas. A necessidade de um templo está na memória dos habitantes. Lucia, criancera* ${ }^{*}$ cantora, rezadora e vereadora na época de minha estada em Las Ovejas, contava que diante da falta de uma capela, quando os missionários chegavam em suas incursões oficiavam missa em casas particulares. Então, organizou-se uma comissão para juntar dinheiro e construir uma "capelinha de palha e barro". Atribui-se o planejamento desta empresa à família Solís, que administrou a construção da capela e decidiu trazer o santo:

[...] esse senhor foi pagar uma promessa em Yumbel e comprou um santo para trazer, e pediu que o trouxessem de carro até San Fabián. Dali pagou a outro senhor, que se chamava [yamaba] Juan Méndez, que tinha uma mula, e a Ruben Robrigues. Viajaram para o Chile, porque daqui todo mundo ia ao Chile comprar sua mercadoria para o inverno; e esse senhor trouxe em lombo de mula o santinho São Sebastião, em uma mula mansinha. Puseramno em um caixote, guardaram-no e o trouxeram; e assim chegou por intermédio da família Solís. Don Alfonso Solís foi o que trouxe o santo; e o colocou nessa capela que se fez ad honorem com todo o mundo.

Lucia refere-se a uma série de aspectos que são de grande importância para os objetivos de minha análise. O primeiro, que pudemos apreciar em parágrafos anteriores, está relacionado com a fonética castelhana. Em Las Ovejas, em geral, todos se consideram descendentes de chilenos, mas, ao mesmo tempo, dizem que "não falam como chilenos". Embora nem todos o pronunciem, o y que Lucia e outros habitantes utilizam para termos yamava ou cabayo é um dos signos da nacionalização argentina e da hegemonia portenha. O castelhano é comum a ambos os lados da fronteira, mas a forma de falar e de pronunciar é, em seus próprios termos, um dos aspectos que hoje em dia diferenciam uma nacionalidade da outra ${ }^{4}$. Em segundo lugar, Lucia faz menção a um aspecto economicamente relevante para a época ao dizer que "todo mundo ia ao Chile comprar sua mercadoria para o inverno", tema que desenvolverei mais adiante. Por último, ela afirma que, por intermédio da família Solís, um outro habitante de Las Ovejas "comprou um santo" em Yumbel. Diferentemente de Barreto, Lucia aponta como sujeitos da proeza seus convizinhos e não o missionário Gardín. O fato de Lucia assegurar que a imagem foi trazida por eles e por

\footnotetext{
* N. T. - Os criadores de gado caprino ou ovino do interior rural se identificam com o apelativo de
} crianceros(as). Abarca desde minifundiários até produtores com certo grau de capitalização. 
sua própria decisão, sem nenhuma ajuda institucional, nem da igreja, nem do governo, reforça a gesta e acentua a agência e decisão dos habitantes. Mas, além disso, está confirmando a versão mais difundida na atualidade (ou a que, ao menos, maior quantidade de vezes me foi relatada em minha condição de investigador portenho) sobre a origem da importação do santo. Alega que de Yumbel a imagem foi transportada a San Fabián e dali passou à Argentina. San Fabián fica em território chileno e na altura de Las Ovejas. O relato indica que por ali a imagem foi trazida diretamente, sem que houvesse inconvenientes fronteiriços com autoridades argentinas ou chilenas para cruzar por essa passagem transandina. Esta não é a única versão. Outras, sem necessariamente contradizer a de Lucia, acentuam outras dimensões relacionadas à economia e às transformações políticas que ocorreram na região durante a década de 40.

\section{São Sebastião representava um saldo negativo para a economia argentina}

Um aspecto que se faz evidente em relatos de alguns autores, assim como na análise de Gregorio Alvarez, folclorista que presenciou a celebração do santo em 1961, é o fato de o tráfico transandino ser considerado um problema para os interesses argentinos. A festa de Yumbel era parte desses inconvenientes, sobretudo pela descarga de dinheiro que implicava devido à crença na possibilidade de poder manipular em favor pessoal os poderes do santo a partir do pagamento por milagre.

Gardín insistia, em suas prédicas missionárias, no culto aos santos como protetores e intermediários diante de Deus. Por exemplo, na inauguração da capela de Los Menucos, dedicada a São José, demonstrou publicamente aos habitantes que os santos podem ser manipulados em interesse próprio. Escreve em suas memórias compiladas por Barreto que:

No sábado esgotou-se-me a paciência (devido a um impetuoso e contínuo vento) e de pé diante da imagem do Patrono que acabo de colocar, desafioo, comprometo-o e contrato com ele um dia tranqüilo e esplêndido para amanhã, dia de sua festa: logo continuo o trabalho. No dia seguinte, efetivamente, amanheceu como uma nova criação. Graças a Deus pela intercessão do Santo (1985:71).

Gardín acreditava e infundiu na população, de acordo com os postulados da Igreja Católica anterior ao Concílio do Vaticano II, que os santos 
são seres excepcionais e que atuam como intercessores diante de Deus para gerar ações extraordinárias. Em sua concepção se podia fazer um contrato com o santo para, por exemplo, eliminar um fenômeno climático. Neste contrato não existia apelativo moral nem rogação de piedade diante da divindade: o vento era um incômodo para a realização de uma festa correta; e se podia "ralhar" com o santo para que utilizasse seus poderes com o objetivo de parar o vento.

Os habitantes manifestavam uma concepção similar em relação aos santos, que eram (e são) sobretudo reverenciados por serem considerados capazes de produzir milagres: ações extraordinárias que vão além do que um homem considera poder realizar em suas ações cotidianas. Para conseguir esses favores é necessário estabelecer uma relação de intercâmbio com a divindade em questão, e os milagres devem ser pagos. No caso de São Sebastião paga-se em dinheiro ou em sacrifícios de algum tipo; do contrário, corre-se o risco de sofrer algum castigo por parte do santo. Por exemplo, Alvarez nota que um dos pontos centrais do festejo é a manda, e acrescenta que "não há exemplo de alguém que tenha descumprido esse sagrado dever, porque se não for cumprido acarretará maiores infortúnios" (1968:84). A manda é uma prática que consistia (e consiste) em deixar dinheiro na capela onde estivesse a imagem de São Sebastião, em agradecimento a seus favores.

Pelos motivos assinalados anteriormente, alguns relatos acentuam o fato de que uma importante soma de dinheiro ficava no país vizinho. Esta seria a razão pela qual se decidiu importar a imagem. Como diz Elías, comerciante oriundo de Andacollo e hoje residente em Buenos Aires:

As pessoas naquela [en aqueya] época, eu me lembro, iam ao Chile. As pessoas daqui iam ao Chile pagar a manda do santo, e ia muito dinheiro para o Chile, e ia muita gente para o São Sebastião. Mas não era tanto por irem ao Chile, mas porque o que chamava a atenção é que levavam todo o dinheiro. Então disseram, o que está acontecendo aqui? A grana [guita] levam [yevam] para outro lugar. Então vamos tratar de trazer, de fazer uma capela [capiya]. Bom, se fez a capiya de São Sebastião, mas tinha que se trazer o santo. Assim que o foram buscar no Chile.

\section{Ou Alvarez:}

As 'mandas' ou pedidos que se formulavam ao santo antes da construção da atual capela em Las Ovejas deviam ser 'pagas' pessoalmente em Yumbel, que era onde se considerava que era a sua sede, mas desde $1960^{5}$, já se 
'pagam' na própria localidade de Las Ovejas, que se erigiu como sede neuquina (1968:84).

Tanto na versão do filho de um homem que, na mesma época de importação da imagem, era comerciante naquela zona e, por conseqüência, diretamente envolvido com o comércio transandino, quanto na de Alvarez, acentua-se que a criação de uma sede local para a imagem de São Sebastião referia-se principalmente a motivos econômicos, pois o dinheiro das mandas devia permanecer na Argentina.

Pablo, um ex-padre que missionou na década de 70 junto com Gardín, me contou não ter sido de todo fácil acostumar os habitantes à nova sede da festa. De todo modo, os moradores do Alto Neuquén começaram paulatinamente a freqüentar maciçamente a sede de Las Ovejas em detrimento da de Yumbel. Paulatinamente, dizemos, porque nas Crónicas da missão salesiana de Chos Malal não existe referência à festa até 8 de janeiro de 1953; e logo em 23 de janeiro de 1956 se expõe uma descrição com algum detalhe:

Às 15:05 regressa [a Chos Malal] o R. P. Pedro Rotter de sua frutífera missão pela paragem Las Ovejas [...]. Em 9 de janeiro partiu a cavalo para Las Ovejas — quase sete léguas. Ali ministrou a reza da novena de preparação para a festa de São Sebastião, titular da capela local. O tríduo foi concorrido, com fervor crescente. Em 20 de janeiro, dia do santo, umas 1.500 pessoas assistiram à missa, que teve de ser celebrada ao ar livre (Crónicas).

Em 1961, Alvarez (1968:81) calculou em 5.000 o número de fiéis presentes na festa, quando a localidade contava com 500 habitantes. Assinala que a afluência provinha tanto de Neuquén quanto do Chile.

\section{Sebastião, santo protetor dos contrabandistas}

Embora nem todos os seus habitantes atualmente estejam dispostos a considerá-la como verdadeira, outra versão assinala que a imagem ingressou em Las Ovejas, e portanto em território argentino, por contrabando. A instalação da Gendarmeria Nacional na região impôs fortes interdições nas passagens da cordilheira, exceto naquelas autorizadas e sob pagamento dos impostos aduaneiros correspondentes, autorizações que não existiam na Zona Norte. Diante da impossibilidade de atravessar a fronteira de uma maneira legal, os moradores do lado argentino pe- 
diram auxílio ao padre Gardín para que ajudasse a trazer uma estátua de São Sebastião, pois eles já não podiam comparecer a Yumbel. Assim relata (acentuando a agência do clero e não da população) Isidro Belver, antigo padre e historiador regional, para quem a imagem foi importada como uma resposta ao fechamento da fronteira:

No Chile, o lugar privilegiado de seu culto é o povoado de Yumbel, aonde acorriam em todos os 20 de janeiro crianceros do norte neuquino para 'pagar a manda' e agradecer as graças concedidas. Pelo ano de 45 , fechada a fronteira e com a vigilância estrita da Gendarmeria, o que antes era um comércio habitual e um trânsito fluido se converteu em contrabando. O padre Gardín, com bom tino, começou a levantar uma humilde capela em Las Ovejas que logo se converteu no centro das peregrinações da Zona Norte. Mas era necessária uma imagem do santo, 'tinha que ser de vulto'. O mais apropriado era trazê-la do Chile, mas os guardas não deixavam ninguém passar. O missionário encarregou um morador de fazer o impossível para trazer uma imagem do santo. Com grande risco, conseguiram trazê-la de contrabando, mas para dissimular levaram-na a Chos Malal e dali a trouxeram para o missionário como se a houvessem mandado de Bahia Blanca. Ninguém acreditou nessa viagem e menos ainda os guardas que denunciaram o missionário por contrabando e queriam apreender o santo. E ainda que todos soubessem que São Sebastião fora trazido do Chile - só se quebrou um dedo - ninguém pôde comprovar o contrabando e dizem que desde então o santo adquiriu fama de ajudar muito especialmente os contrabandistas (1990).

Segundo esta versão, a imagem não entrou no país pela passagem das lagunas de Epulaufquen, por onde, segundo o primeiro relato que apresentamos, a imagem foi importada, mas pela passagem Pichachén, mais próxima de Chos Malal. Ambas as passagens estavam oficialmente fechadas, mas passá-la por Pichachén permitiu que a imagem chegasse primeiro à missão salesiana e de lá Gardín pôde enviá-la para Las Ovejas a pretexto de que a havia comprado na Argentina.

Os que afirmam que esta versão é verdadeira acrescentam que antes que a Gendarmeria de instalasse "não havia argentinos nem chilenos", mas que os habitantes simplesmente "andavam de um lado para o outro da cordilheira" 6 . Conseqüentemente, tampouco existia a palavra contrabando, tratando-se antes de um tráfico comercial ou escambo. Segundo Elías:

[...] naquela [en aquella] época não era contrabando, as pessoas vendiam seus produtos no Chile. Era um comércio, apesar de ser proibido. Mas não 
estava no Mercosul como agora; as pessoas em momentos de desespero levando suas carguinhas de gordura, de sabão ou óleo que se levava para o Chile. Afinal, por ali apareciam os guardas, os caras se escondiam e nesse momento de desespero o primeiro que faziam era lembrar-se do santo e faziam a ele uma manda, uma promessa; aquele que se saía bem ia depois e pagava ao santo, e se vê que corria bem, porque muita gente ia lá, juntava muita grana no 20 de janeiro.

A Gendarmeria não pôde evitar completamente o tráfico transandino. Quando perseguia os que atravessavam (agora ilegalmente) a Cordilheira e os (agora) contrabandistas, estes, se consideravam provável a sua captura, se encomendavam ao santo. Daí dizer que São Sebastião protegia os contrabandistas. Como estes, por sua vez, eram os que mais tinham dinheiro na Zona, eram eles os que maiores mandas ofereciam durante a festa.

A partir de então atividades cotidianas converteram-se em ilegais, gerando um conflito de valores entre a população e a legislação estatal e, sobretudo, produzindo a bancarrota da economia regional. Assim Jorge Fernández, arqueólogo que trabalhou diversos aspectos dessa Zona, descreve a situação da região em meados da década de 60:

Era no contrabando para o Chile que os excedentes encontravam mercado fácil ou ao menos factível; e, na verdade, torna-se doloroso denominar contrabando, comércio ilegal, o que definitivamente não era mais do que um comércio perfeitamente harmônico entre duas comarcas que, ainda que separadas pela linha artificial do limite, complementavam tão bem suas necessidades econômicas [...]. Não por ambição de ganhar, mas por uma necessidade natural, quase inelutável, o habitante do Alto Neuquén se viu obrigado a exportar por sua conta e risco o gado que lhe sobra, mesmo quando essa especialíssima exportação fosse considerada tráfico ilegal. Não fazer tal contrabando significava povoar excessivamente seus campos de invernada, incapazes de suportar um pastoreio excessivo; significava, enfim, necessidades incontáveis para ele e sua família [...]. O contrabando, esse tráfico ilegal, foi eliminado mediante perseguição [...]. Os resultados são fáceis de observar: famílias inteiras de crianceros perderam seus bens, trabalhosa e honradamente ganhos, por causa de não poder vender, por causa de superpovoar os escassos campos naturais de pastoreio (1965:53).

Ainda que o relato resulte um tanto idílico, já que se refere a "um comércio perfeitamente harmônico" ou a comarcas que "complementa- 
vam tão bem suas necessidades econômicas", descreve com bastante fidelidade o ocorrido. Além disso, se considerarmos o relato anterior de Elías, veremos que existe certa similitude em relação à afirmação de que aquela atividade, naquela época e naquela região, era considerada mais "comércio" do que "contrabando". Por outro lado, Elías afirma que apesar do perigo da Gendarmeria, "as pessoas em momento de desespero" atravessavam a cordilheira. Da mesma maneira, Fernández diz "não por ambição de ganhar, mas por uma necessidade natural [...] o habitante do Alto Neuquén se viu obrigado a exportar por sua conta e risco o gado que lhe sobra". O relato do acadêmico e o do comerciante local coincidem em assinalar que para os habitantes daquela região, quando do fechamento da fronteira, o comércio com o Chile deixou de ser uma alternativa, e que diante da falta de outras possibilidades na região, a própria sobrevivência material dessas populações perigava.

O fechamento da fronteira em meados da década de 40 somado à falta de vias de comunicação com o resto da Argentina produziram efeitos catastróficos para a economia regional. Conseqüentemente, às famílias que não se arriscaram no contrabando não restou outra saída além da migração. Esta foi intensificada no início dos anos 60, quando começaram no centro da província grandes obras de irrigação e viárias, e a demanda de mão-de-obra viu-se aumentada pela intensificação da atividade petroleira e pelo crescimento da fruticultura.

\section{Visibilidade ou invisibilidade das relações interandinas?}

Diego Escolar afirma que na província de San Juan, onde também se observa na mesma época um corte nas relações transandinas, as fontes diplomáticas e historiográficas dos Estados argentino e chileno invisibilizaram a cordilheira como área de produção, socialidade e intercâmbio (2001: 261). E que, "ao contrário do [que propõe o] imaginário nacional da 'muralha andina', os Andes constituem o centro e não o limite para uma comunidade transandina" (:147). Não obstante, essa invisibilidade e esse imaginário da muralha andina se contrapõem a outras idéias, também geradas nas metrópoles, que negam a Cordilheira como limite.

Nas cédulas reais de 15 de maio de 1669 e de 21 de maio de 1684 estipulava-se que na zona austral o limite ocidental da Governança de Buenos Aires era a Cordilheira dos Andes, limite natural do reino do Chile (Lacoste 2001:197). Essa idéia de fronteira natural expressa na forma de uma cadeia montanhosa tinha um especial atrativo para os diploma- 
tas e homens de Estado do século XVII, e a Espanha utilizou-a não apenas para essa situação colonial, mas também em seu próprio território, onde a idéia dos Pirineus como cadeia montanhosa que divide a França da Espanha começou a circular em 1659 com o Tratado dos Pirineus (Sahlins 1989:30). Tal concepção se prolonga até começos do século XIX, e as próprias constituições chilenas de 1822 e 1833 ratificam-na.

O estampido da questão dos limites produz-se em meados do século XIX. Este é o momento em que, tal como na Europa, encontramos aqui a necessidade de marcar a fronteira por uma linha que manifeste permanentemente a soberania territorial (Sahlins 1989:28). Entretanto, se com o declínio dos estabelecimentos militares o princípio da fronteira natural perdeu peso na Europa, em nosso caso este princípio parece fundir-se com aquele dos direitos históricos. Entre 1852 e 1881 elaboraram-se teses que abandonavam a idéia da cordilheira como limite natural, como por exemplo o texto de Manuel Ricardo Trellez, “La cuestión de límites entre la República Argentina y el gobierno de Chile, Buenos Aires, 1865", que afirma que em 1810, no momento das revoluções independentistas, pertencia à Argentina todo o atual território chileno localizado ao sul do rio Bio-Bio (Lacoste 2001:217). Mas o tratado de 1881 derrotou essa idéia. Os territórios do sul das atuais Repúblicas do Chile e da Argentina foram conquistados às populações indígenas quase que simultaneamente por ambos os exércitos, o que tornou manifesta uma série de conflitos limítrofes. No Tratado Bernardo de Irigoyen-Borja Echeverría, de 1881, estabeleceu-se o limite entre os países segundo a linha mais elevada dos cumes da cordilheira, que dividem as águas. Este tratado não satisfez os governos de nenhuma das partes, dando lugar a anexos complementares em 1889. Em 1895 firmou-se um tratado adicional que deu à Argentina o direito ao Atlântico e, ao Chile, o direito ao Pacífico. Entre 1898 e 1900 foram protocolados os convênios Zeballos-Matte e Alcorta-Subercaseaux pelos quais se estabelecia que o avanço de qualquer dos dois países em território sujeito a arbitragem seria considerado uma violação dos pactos preexistentes. Em 1902 deu-se como solucionado o problema mediante a assinatura dos Pactos de Maio, que compreendem um tratado geral de arbitragem e um pacto de limitação de armamentos (Rodríguez Molas 1983:14). Dessa maneira, e acima dos interesses contrapostos e das disputas restritas a certos trechos da demarcação, triunfou a idéia de que a cordilheira era o lugar natural para colocar a linha de fronteira entre os dois Estados. Por exemplo, em um documento do governo chileno de 1902, “Exposição que por parte do Chile e em resposta à exposição argentina se submete a tribunal constituído pelo governo de sua majestade 
britânica em seu caráter de árbitro nomeado pelo acordo de 17 de abril de 1896", pode-se encontrar uma capa composta por uma foto destacável da cordilheira, que tem escrito no rodapé:

A espessa e empinada cordilheira dos Andes estendida de norte a sul como uma muralha gigantesca [...]. Mole imenso de neve e granito [...] se lançará sempre majestosa e quase inviolável para os exércitos que contrariando os desígnios de Deus e as indicações do destino manifesto dos dois povos pretendam escalá-la com fins de predomínio e ambição (apud Escolar 1997).

No entanto, a tensão entre o princípio da fronteira natural e a tese dos direitos históricos que a negam sempre foi vigente. Durante grande parte do século XX, tanto na Argentina como no Chile, fez-se tradição ensinar que em 1810 ambas as nações abarcavam um território muito maior do que possuem na atualidade: a Argentina tinha territórios no Pacífico e o Chile tinha a Patagônia, que foi perdida (Lacoste 2001:191).

Quanto aos habitantes das cordilheiras, eles não as tomaram como barreira intransponível e amiúde assumiram-nas como área central de produção e intercâmbio. Na verdade, para eles, a Cordilheira não é uma fronteira natural. Para além das discussões a respeito da visibilidade ou invisibilidade das relações conduzidas pelos organismos oficiais, o comentário de alguns habitantes de que antes da instalação da Gendarmeria não havia nem argentinos nem chilenos, somado às práticas econômicas, religiosas e culturais que havia na região, indicam o momento em que se delimitou efetivamente (além dos tratados internacionais acordados) a fronteira internacional no Alto Neuquén. Isso acarretou uma série de transformações no cotidiano dos seus habitantes: por um lado, fortaleceu a identificação nacional, mas ao mesmo tempo produziu uma crise nas economias rurais e conduziu à aparição de um novo ator social: o contrabandista.

Esses processos parecem reafirmar a teoria de que os Estados-nação hispano-americanos se construíram de cima para baixo. Unidades administrativas da colônia espanhola foram concebidas como pátrias e os neologismos criados pelos crioulos ilustres dos atuais países latino-americanos definiam as populações como compatriotas antes que fossem constituídas como tais (Anderson 2000). Encobrindo essas denominações diferenças entre povos que certas vezes nem sequer falavam uma língua comum, no futuro e por suas respectivas constituições, os habitantes desses conglomerados seriam, todos eles, partes de uma nação diferenciada das vizinhas. Na América Hispânica, os reinos e cidades precederam tanto o Estado quanto a nação e o problema foi, no caso das cidades, como cons- 
truir, partindo de uma mesma "nacionalidade" hispânica, Estados-nação diferentes (Guerra 1992:320). No entanto, para as áreas tardiamente anexadas, o postulado parece ter sido o inverso, e as novas nações viram-se obrigadas a destruir organizações sociais anteriores e muito diversas entre si para conseguir impor sua legitimidade.

As nações e seus limites internacionais são historicamente construídos e imaginados no sentido de Anderson. Mas também deve-se acrescentar que o conteúdo do que significa pertencer a uma nação não é unívoco para toda a população; e que, ademais, esses conteúdos estão continuamente em negociação, interpretação e recriação pelos que vivem na fronteira, pelos que a cruzam e pelos que, apesar dos limites impostos pelo Estado, sentem que têm algo em comum com os que estão fora do limite (Donnan e Wilson 1994:11). Por isso, sustento que, em princípios do século XX, no Alto Neuquén, a fronteira internacional era um limite artificial e uma imposição estatal na percepção dos seus habitantes. Mas, em meados do mesmo século, as atividades do Estado nacional, representado no caso pela Gendarmeria, e da Igreja Católica, representada pela Ordem Salesiana, embora cada um com diferentes interesses, contribuíram para nacionalizar os habitantes.

Isso não foi casual. Fez-se em um momento da história argentina em que o Estado se caracterizou por reforçar sua presença na vida social e no território nacional (ou que paulatinamente se foi nacionalizando). Mesmo que se possa pensar isto como um atributo do "Estado peronista" (19451955), na realidade, a estratégia remonta já a governos anteriores, e a presença da Gendarmeria na região é parte de toda uma reconfiguração das relações centro/periferia que se sucede na Argentina nessa época.

A necessidade de "nacionalizar" esse território estava presente há muito tempo. Basta como exemplo a análise que fizemos das crônicas de Carbajal. Mas a concretização efetiva de tudo isso só começou a ser implementada na década de 40, tendo se aprofundado com o chamado "Estado peronista". Ao mesmo tempo, esse é um período em que a história da Igreja Católica se confunde com a história "profana" do país. Naqueles anos, a Igreja instalou-se no centro de disputas políticas e ideológicas. O renascimento católico argentino a partir do Congresso Eucarístico de 1934 foi uma contra-ofensiva ao liberalismo e se propôs a reconquistar o Estado e convertê-lo em instrumento da recristianização da sociedade (Di Stefano e Zanatta 2000).

Diante desse processo intensivo de nacionalização, a festa de São Sebastião em Yumbel aparecia como um ranço de um tempo que se devia esquecer. A celebração quando Neuquén era Território Nacional es- 
tava inter-relacionada com a economia e a cultura do Pacífico e, por isso, a Gendarmeria impediu essa prática religiosa. Por sua parte, os habitantes, muito possivelmente junto com os clérigos e em um processo de reinvenção cultural, trouxeram e argentinizaram São Sebastião.

\section{Duas nações, dois santuários}

A nacionalização desses territórios assinalou a reacomodação e a criação de novos centros e periferias. A emergência do novo centro que seria Buenos Aires manifestou-se nessa região periférica através da chegada de funcionários de caráter distinto. No caso em pauta, destaque-se o papel da Gendarmeria e dos missionários, que atuaram como "mediadores" (Silverman 1967:279), servindo de conexão entre as localidades e o Estado central, e ajudando a recriar o culto em um estilo "mais argentino". Uma das formas pelas quais isso se plasmou foi a partir da criação de um novo centro religioso separado de seus vizinhos chilenos ${ }^{7}$. Nessa nacionalização os padres desempenharam um papel importante: em primeiro lugar, ao permitirem erigir uma capela em nome de São Sebastião; em segundo, porque os salesianos modificaram as canções que durante a festa de celebração do 20 de janeiro faziam referência ao Chile, algo que, segundo me contou Pablo, incomodava a Gendarmeria. Isso se reflete em alguns versos do Hino a São Sebastião que atualmente se canta em Las Ovejas e em Yumbel, respectivamente:

Protetor de Neuquén, Sebastião

(...)

Nosso povoado argentino te aclama $(\ldots)$

Protetor desta igreja nortista
Protetor de Yumbel, Sebastião

(...)

Nosso povoado chileno te aclama $(\ldots)$

Protetor desta igreja chilena

O sentido das canções, do ponto de vista religioso, não muda, e São Sebastião é para as duas igrejas um padroeiro protetor, assinalando a ecumenicidade da Igreja Católica. Mas há uma transformação fundamental, pois em um caso Sebastião protege Yumbel e o Chile, e no outro, Neuquén e a igreja nortista; em um, aclama o povo chileno, em outro, o argentino. A nacionalização efetiva-se, nesse caso, de maneira similar à que Anderson (2000:204) assinala para os hinos nacionais, nos quais existe ao cantá-los uma experiência de simultaneidade: pessoas às vezes desconhecidas entre si, pronunciaram simultaneamente os mesmos versos e melodia. 
Outro processo de nacionalização relativo à ação dos missionários não concerne aos chilenos, mas aos Mapuche. Um dos eventos rituais da festa de São Sebastião em Las Ovejas, em meados do século XX, foi o simulacro de malón. Habitualmente denomina-se malón às incursões guerreiras e aos saques que os Mapuche antes de 1879 faziam nas povoações crioulas do Pampa. Os padres transformaram essa prática em um símbolo de argentinidade e cristandade. Assim o descreve o primeiro bispo de Neuquén, Jaime De Nevares, em uma carta enviada à sua família de Buenos Aires em 1962 e publicada em sua biografia escrita por Juan San Sebastián:

Por fim, o P. Gardín enviou ao cimo de uma elevação o cavaleiro que levava uma cruz e os dois que o flanqueavam com a bandeira Papal e Argentina, e, uma vez ali, açulou aos que ficaram, e em um momento se destacou um verdadeiro malón de 300 cavaleiros que alcançaram os anteriores e baixaram a colina saltando fendas a todo galope. Uma araucana de idade, montada, entusiasmada: 'assim é que eu gosto, a moçada em defesa da cruz e da bandeira'. Viu mais profundo que a maioria o que podia haver de simbólico. (1997:166).

Nesta citação sobrepõem-se três elementos: a) a cruz da bandeira Papal, signo da Igreja Católica; b) a bandeira argentina, signo da soberania desta nação sobre esse território; e c) o malón, prática de guerra mapuche contra os espanhóis e crioulos. Tenhamos em conta que o relato é do bispo e conseqüentemente apresenta certa tendência para seus próprios interesses. Além disso, o texto assinala que ao menos uma das mulheres que participaram no malón era uma araucana (Mapuche) idosa. Isto, por um lado, nos diz que compareceram à festa membros declarados como Mapuche, situação que também me foi relatada pelos habitantes. Por outro, essa araucana era "de idade", ou seja, anciã. Como tal, pode ter sido testemunha da invasão argentina na região e da posterior desarticulação de sua sociedade. No entanto, mostra estar satisfeita com o fato de os jovens defenderem, por meio de uma prática bélica indígena, os que os venceram militarmente e lhes desarticularam a cultura: os argentinos e os clérigos. Dessa maneira, o hino a São Sebastião e outros eventos, como o simulacro do malón, assinalam que a festa em Las Ovejas começou paulatinamente, após 1940, a ser integrada a uma suposta "tradição nacional argentina", vinculada ao chileno e ao Mapuche, mas ao mesmo tempo separada deles.

Mas a argentinização da festa empreendida pelos padres não impediu que um setor da população comprometido com o comércio transandino 
ressignificasse São Sebastião contra a legislação imposta pelo Estado argentino. Fazer de São Sebastião um santo protetor dos contrabandistas implicava dotá-lo de um elemento subversivo. A própria Constituição Nacional argentina atesta no artigo 2o que "O Governo federal mantém o culto apostólico católico romano" (Constitución da la Nación Argentina 1996:6), ou seja, que a religião oficial do Estado é a católica. Portanto, os poderes das autoridades terrenas ou divindades sobrenaturais desse culto não podem contradizer a legislação do Estado. Porém, o relato que sustenta que um missionário da Ordem Salesiana encarregou alguns habitantes de trazerem do Chile uma imagem de um santo contrabandeada para edificar uma igreja em território argentino, e que, em seguida, o êxito desta empresa fez com que São Sebastião de Las Ovejas se convertesse no protetor dos que desafiavam o Estado argentino através do contrabando, estava, a despeito da veracidade dos fatos, legitimando uma versão da história que não convinha nem aos interesses do Estado argentino nem aos da Igreja Católica, pois jogava uma instituição contra a outra. Apesar disso, é ainda uma versão que ratifica a fronteira. A qualificação exclusiva do comércio transandino como contrabando e, conseqüentemente, como atividade ilegal, dando lugar à aparição de um santo protetor dos contrabandistas, contribuiu para naturalizar o limite internacional, assim como o fez a legislação oficial em torno da fronteira. A travessia ilegal confirma a cordilheira como limite imposto por um Estado e como espaço de normas estritas, cuja infração implica a possibilidade de castigos. Assim, a realização de atos de autoridade é em si mesma uma ação integradora (Shils 1996:146) que atraiu os habitantes ao novo centro.

\section{Conclusões}

A associação entre os missionários e a Gendarmeria Nacional para argentinizar o cristianismo na região nos faz reavaliar a crítica de Lomnitz (2001: 48) a Anderson a respeito do papel da religião na conformação dos nacionalismos na América Latina. Esta exposição mostra que o nacionalismo não necessariamente substitui a religião, mas que muitas vezes inclusive se apóia nela. Na verdade, essa associação entre religião e nação não é só um capricho de grupos de poder. É a própria população que exige que a religião (em seu caráter institucional ou "popular") esteja presente nos processos políticos e econômicos. Ao incorporar a perspectiva dos atores, percebemos que de alguma maneira "o santo se impôs". Seguramente, teria sido mais prático para os missionários e para a Gendarmeria colocar 
como padroeiro outro santo que não estivesse associado "ao chileno". No entanto, não puderam. Com isso não quero acentuar a agência do santo, mas da própria população, arraigada a uma tradição, mas com capacidade suficiente para recriá-la e inventar uma nova. Tampouco significa que por trás dela exista uma comunidade anterior e mais concreta que a imaginada atualmente, mas uma reacomodação à nova situação estrutural de reconfiguração dos espaços nacionais ocorridos na Argentina em meados do século XX, e que hoje possuem tanta eficácia quanto em outros tempos a tiveram as comunidades anteriores.

Verificamos também que, tal como afirma Lomnitz (2001:47), o nacionalismo se desenvolveu gradualmente, começando pelas pretensões diplomáticas coloniais e nacionais do século XIX, passando pela ocupação militar do território, e a posterior demarcação de uma linha de fronteira, até finalmente o fechamento e a eliminação das relações transandinas. Se alguns autores consideram que isto implicou uma invisibilização dessas relações, nós afirmamos que a teoria oficial da muralha andina parece ser mais uma solução diplomática e militar para um fato constantemente visualizado: que as passagens andinas eram vias importantíssimas de tráfico de bens e pessoas. Por isso, mais que invisibilidade encontramos a decisão oficial de cortar esses laços por meio da intervenção de agentes estatais e religiosos sobre o território e seus habitantes, que mediante atos de autoridade reformaram as normas e costumes locais com o objetivo de criar duas nações diferentes com seus respectivos centros políticos, econômicos e religiosos.

Recebido em 27 de fevereiro de 2002

Aprovado em 20 de dezembro de 2002

Traduzido por Jorge Villela

Rolando Silla desenvolve pesquisa de doutorado sobre antropologia da religião no PPGAS/Museu Nacional/UFRJ. 


\section{Notas}

* Uma versão anterior deste artigo fez parte de minha dissertação de mestrado em antropologia social na Universidade Nacional de Misiones (orientada pelas Dras. Rosana Guber e Claudia Briones), depois reformulada para o curso Antropologia do Poder, ministrado pelos professores Federico Neiburg e Marcos O. Bezerra no PPGAS/Museu Nacional/UFRJ. A todos eles devo agradecer por suas sugestões e comentários. O trabalho de campo foi financiado por uma bolsa do CONICET e realizado durante os meses de janeiro e outubro de 1999 e janeiro e fevereiro de 2000

1 Por exemplo, do ponto de vista legal, as taxas aduaneiras que, implementadas pelos dois países a partir de 1897, se caracterizaram por uma série de idas e vindas, com momentos de flexibilização, endurecimento e inclusive suspensão (ver Norabuena Carrasco 1997; Debener 2001; Bandieri 2001). Mas se, como em nosso caso, nos centrarmos na perspectiva dos habitantes, verificaremos que ao se referirem a essa época eles não se mostram tão preocupados com a legislação (cuja implementação é mais que duvidosa na região), mas antes com a presença ou ausência efetiva dos organismos de controle fronteiriço como a Gendarmeria Nacional.

2 Os estudos sobre identidade insistem que os traços que importam para identificar um grupo étnico são os que os atores consideram significativos (Barth 1976:17). Peter Sahlins acrescenta que a adoção de identidades nacionais não necessariamente desloca as locais e/ou étnicas (1989:165), ao que acrescentaríamos a possibilidade de aceitar mais de uma identidade nacional. Embora esses autores reconheçam que a etnicidade não seja produto do isolamento, mas da interação, a insistência mantém-se nas dicotomias entre um grupo e outro. Em nosso caso, encontramos essas dicotomias entre argentinos, chilenos e índios; mas a questão central é que também nos deparamos com indivíduos que pareciam permanecer entre essas categorias de identificação, tornando muito confuso distinguir em certos casos um grupo de outro.

3 Não quero afirmar que o padre em questão projetou que ao redor de toda capela rural se construiria um povoado. Seu objetivo era evangelizar, não povoar nem gerar nenhum tipo de desenvolvimento. Entretanto, devemos ter em conta que, enquanto a literatura especializada costuma insistir na marcha de grandes massas populacionais em direção a Buenos Aires, poucos prestaram atenção nos agentes numericamente reduzidos, mas muito significativos, que através de instituições criadas ou expandidas nessa época, como a Igreja ou a Gendarmeria Nacional, tomaram o caminho inverso, deslocando-se do centro para a periferia. Uma visualização desse processo pode ser encontrada em Neiburg (2001)

4 Se a justaposição uma língua, uma nação, foi fundamental no processo de nacionalização europeu (Anderson 2000), não foi assim na constituição das nações 
hispano-americanas, pois as unidades administrativas coloniais falavam um só idioma. Não obstante a relatividade desta afirmação, já que grandes contingentes só falavam línguas nativas como o mapuche, o castelhano era a língua comum transnacional. Mas a entonação é o que distingue uma nação de outra ou, no caso argentino, uma província. Como o catalão na fronteira franco-espanhola foi, a partir do fim do século XIX, influenciado, simultaneamente, pelo espanhol e pelo francês devido à escola, à imprensa ou ao serviço militar (Sahlins 1989:262), no nosso caso, as instituições e agentes dos centros administrativos estimulavam que se diferenciasse uma mesma língua. Outra interpretação possível é que falassem como portenhos só na minha presença. Ainda que assim seja, isso igualmente evidencia que agora o centro é Buenos Aires e que este representa a nação argentina.

5 O folclorista não acerta na datação da importação da imagem. Considera a chegada recente, quase simultânea ao momento de sua visita a Las Ovejas.

6 Isso poderia equiparar-se ao que Alejandro Grimson (2000:228) assinala para a fronteira entre Encarnación (Paraguai) e Posadas (Argentina), em que afirmações como "a fronteira não existe" significa uma posição ante a fronteira mais do que uma descrição dela. Ainda mais quando em nosso caso são principalmente pessoas que estiveram envolvidas no comércio transandino que o dizem. Não obstante, devemos ter em conta que em Las Ovejas essas afirmações sempre remetem ao passado, não fazendo referência à situação atual, quando a legitimidade da fronteira e da nação não parece estar em questão.

7 Na Europa antes de Napoleão, os limites das unidades administrativas da Igreja Católica não respeitavam os limites dos Estados nacionais. Como a delimitação precisa do território não era considerada uma necessidade, a perda de uma guerra não acarretava perda de território; e se costumava oferecer a administração religiosa ao país perdedor a título de compensação financeira (Sahlins 1989:27). No caso da comunidade da fronteira franco-alemã estudada por Tomke Lask, esse deslocamento se deu até 1939, quando todos acorriam para a igreja do lado alemão. Com a construção de uma igreja francesa, a fronteira linear apoiou-se em uma fronteira "espiritual" e, de maneira similar ao nosso caso, começa uma vida religiosa separada de seus vizinhos (Lask 2000:65). 


\section{Referências bibliográficas}

ALVAREZ, Gregorio. 1968. El tronco de oro. Buenos Aires: Editorial Pehuén. ANDERSON, Benedict. 2000. Comunidades imaginadas. Buenos Aires: Fondo de Cultura Económica.

ARIAS BUCCIARELLI, Mario. 1999. “El Estado neuquino". In: O. Favaro (ed.), Neuquén, la construcción de un orden estatal. Neuquén: Universidad Nacional del Comahue.

BANDIERI, Susana. 1993. "Actividades económicas y modalidades de asentamiento". In: S. Bandieri, O. Favaro, e Morinelli (comps.), Historia de Neuquén. Buenos Aires: Plus Ultra.

. 2001. "Estado nacional, frontera y relaciones fronterizas en los Andes norpatagónicos: continuidades y rupturas". In: S. Bandieri (coord.), Cruzando la cordillera... La frontera argentino-chilena como espacio social. Neuquén: Universidad Nacional del Comahue.

BARRETO, Oscar. 1985. En las trincheras de Dios. Bahía Blanca: Editorial del Sur.

BARTH, Fredrik. 1976 [1969]. "Introducción". In: Los grupos étnicos y sus fronteras. México: Fondo de Cultura Económica.

BECHIS, Martha. 2001. "De hermanos a enemigos: los comienzos del conflicto entre los criollos republicanos y los aborígenes del área araucopampeana, 1814-1818". In: S. Bandieri (coord.), Cruzando la cordillera... La frontera argentino-chilena como espacio social. Neuquén: Universidad Nacional del Comahue.

BELVER, Isidro. 1990. Malal Meulen. Huingan-Co: Museo del Árbol y la Madera.
CARBAJAL, Lino. 1985 [1906]. Por el Alto Neuquén. Neuquén: Siringa Libros.

CRÓNICAS. (1/9/48-3/6/68; 7/68-2/76; 3/77-4/84). Archivo de la Misión Salesiana de Chos Malal. Manuscrito.

CONSTITUCIÓN DE LA NACIÓN ARGENTINA. 1996. España: Grupo Editorial Océano.

DEBENER, Marcela. 2001. "Frontera agraria y comercio ganadero: Mendoza-Neuquén (1850-1930)". In: S. Bandieri (coord.), Cruzando la cordillera... La frontera argentino-chilena como espacio social. Neuquén: Universidad Nacional del Comahue.

DI STEFANO, Roberto e ZANATTA, Loris. 2000. Historia de la iglesia argentina. Buenos Aires: Editorial GrijalboMondadori.

DONNAN, Hasting e WILSON, Thomas. 1994. "An anthropology of frontiers". In: H. Donnan e T. Wilson (eds.), Borders approaches. Lanham, MD: University Press of America.

ESCOLAR, Diego. 1997. El sueño de la razón y los monstruos de la nación: la naturalización de la frontera andina en el proceso de articulación nacional argentino-chileno. Trabalho apresentado no V Congreso Argentino de Antropología Social, UNLP, La Plata . 2001. "Subjetividad y estatalidad: usos del pasado y pertenencias indígenas en Calingasta". In: S. Bandieri (coord.), Cruzando la cordillera... La frontera argentino-chilena como espacio social. Neuquén: Universidad Nacional del Comahue.

FERNÁNDEZ, Jorge. 1965. "Contribución al conocimiento geográfico de 
la región del Alto Neuquén". IDIA, 207:1-32. Buenos Aires.

FRAPICCINI, Alina, RAFART, Gabriel e LVOVICH, Daniel. 1995. “Migración y fluctuaciones del mercado de trabajo: los trabajadores chilenos de Neuquén, 1884-1930". Estudios Migratorios Latinoamericanos, 30.

GRIMSON, Alejandro. 2000. “El puente que separó dos orillas. Notas para una crítica del esencialismo de la hermandad". In: A. Grimson (comp.), Fronteras, naciones e identidades. La periferia como centro. Buenos Aires: Ediciones Ciccus-La Crujía.

GUERRA, François-Xavier. 1992. Modernidad e independencias. México: Fondo de Cultura Económica.

LACOSTE, Pablo. 2001. "Mapas territoriales e imagen del país vecino: el caso de Argentina y Chile". In: S. Bandieri (coord.), Cruzando la cordillera... La frontera argentino-chilena como espacio social. Neuquén: Universidad Nacional del Comahue.

LASK, Tomke. 2000. "Construcción de la identidad nacional. Sistemogénesis de la frontera franco-alemana". In: A. Grimson (comp.), Fronteras, naciones e identidades. La periferia como centro. Buenos Aires: Ediciones Ciccus-La Crujía.

LOMNITZ, Claudio. 2001. "O nacionalismo como um sistema prático. A teoria de Benedict Anderson da perspectiva da América Hispânica". Novos Estudos CEBRAP, 59:37-61.

MASES, Enrique e RAFART, Gabriel. 1997. "Los trabajadores chilenos en el mercado laboral argentino: el caso Neuquén, 1890-1920". In: C. Norabuena Carrasco (ed.), Faltan o sobran brazos? Migraciones internas y fronterizas (1850-1930). Santiago: Editorial Universitaria de Santiago de Chile. NEIBURG, Federico. 2001. Public sphere and social intimacy: politics and cul- ture in the Argentinean national space, 1946-1955. (inédito).

NORABUENA CARRASCO, Carmen. 1997. “La opinión pública frente a la emigración de los chilenos a Neuquén. 1895-1930". In: C. Norabuena Carrasco (ed.), Faltan o sobran brazos? Migraciones internas y fronterizas (1850-1930). Santiago: Editorial Universitaria de Santiago de Chile.

RODRÍGUEZ MOLAS, Ricardo. 1983. El servicio militar obligatorio. Buenos Aires: Centro Editor de América Latina.

ROSAS, Juan Manuel. 1995. Gramática y diccionario de la lengüa Pampa (Pampa, Ranquel, Araucano). Buenos Aires: Ediciones Theoría.

SAHLINS, Peter. 1989. Boundaries. The making of France and Spain in the Pyrenees. Berkeley: University of California Press.

SAN SEBASTIÁN, Juan. 1997. Don Jaime de Nevares. Buenos Aires: Ediciones Don Bosco.

SHILS, Edward. 1996 [1974]. Centro e periferia. Lisboa: Difel.

SILVERMAN, Sydel. 1967. "The community-nation mediator in traditional central Italy". In: J.M. Potter (ed.), Peasant society: a reader. Boston: Little Brown.

WAGNER, Roy. 1981. The invention of culture. Chicago: The University of Chicago Press. 
Resumo

Este texto analisa relatos que giram em torno de como e por que uma imagem de São Sebastião teve de ser importada do Chile para ser instalada em uma capela do norte neuquino (Argentina). Este fato nos permitirá apreciar uma das maneiras como a conformação do Estado-nação argentino e a implantação de suas fronteiras nacionais foi percebida, significada e vivenciada pelos habitantes fronteiriços. Em particular, iluminará as relações existentes em alguns contextos entre religião e nacionalismo, assim como o fenômeno da invisibilidade/visibilidade das relações intercordilheira.

Palavras-chave Estado, Nação, Fronteira, Santos, Contrabando.
This article analises how and why an image of San Sebastian had to be imported from Chile and settled in a church of north Neuquén (Argentina). This fact will allow us to understand how the emergence of the nation-state in Argentina was perceived, signified and lived by the frontier's inhabitants. Particulary, it will throw some light on the relations between religion and nationalism and on the invisivility/visibility of the relations across the Andean mountains.

Key words State, Nation, Frontier, Saints, Smuggling. 